\title{
A ABORDAGEM SOCIOAMBIENTAL NA EDUCAÇ̃̃O EM CIÊNCIAS COMO CAMINHO PARA A CONSTRUÇÃO DA CIDADANIA NA SOCIEDADE DE RISCO
}

\author{
DEINE BISPO MIRANDA ${ }^{*}$ \\ https://orcid.org/0000-0002-3922-8294 \\ IZABEL CRISTINA BRUNO BACELLAR ZANETI ** \\ https://orcid.org/0000-0002-7484-1799
}

RESUMO: O presente artigo apoia-se no conceito de Risco, abordado em Sociedade de Risco, de Ulrich Beck, e tem por objetivo refletir, no âmbito do espaço escolar, sobre como a Educação em Ciências, pode, por meio do aporte da Educação Ambiental, promover a reflexão sobre os riscos oriundos dos avanços científicos e tecnológicos, de modo a contribuir para a formação da cidadania socioambiental dos atores da referida sociedade de risco. Nesse sentido, realizou-se uma pesquisa exploratória e bibliográfica à luz de Beck (2009; 2011), Beck, Giddens e Lash (1997), Giddens e Sutton (2017), dentre outros. Os dados iniciais apontam para a necessidade da incorporação das práticas ambientais na Educação em Ciências, de maneira a superar o entendimento estrito da visão física, química e biológica do conhecimento, dialogando no contexto social, político e econômico dos riscos, colocados a partir dos avanços científico-tecnológicos, tornando-se parte prioritária e não complementar na formação docente.

Palavras-chave: Risco. Educação Ambiental. Educação em Ciências.

\section{EL ENFOQUE SOCIOAMBIENTAL EN LA EDUCACIÓN EN CIENCIAS COMO CAMINO PARA LA CONSTRUCCIÓN DE LA CIUDADANÍA EN LA SOCIEDAD DE RIESGO}

RESUMEN: Este artículo se apoya en el concepto de Riesgo, abordado en Sociedad de Riesgo, de Ulrich Beck, y tiene el objetivo de reflexionar, en el ámbito del espacio escolar, acerca de cómo la Educación en Ciencias, puede, por medio del aporte de la Educación Ambiental, promover una reflexión sobre los riesgos oriundos de los avances
*Doutoranda do programa de Pós-Graduação em Educação em Ciências (PPGEduC) da Universidade de Brasília (UNB), professora da Secretaria de Estado de Educação do Distrito Federal (SEEDF) e membro do Grupo de Pesquisa Perspectivas Críticas da Educação em Ciências (PPGEduC- UnB). E-mail: deine_miranda@hotmail.com

* *Doutora pelo Centro de Desenvolvimento Sustentável (CDS) da Universidade de Brasília (UnB), professora associada CDS/UnB, membro do Programa de Pós-Graduação do CDS - UNB, membro da Câmara de Extensão UnB e Coordenadora do colegiado de Extensão do CDS-UnB. E-mail: izabel.zaneti@yahoo.com 
científicos y tecnológicos, para contribuir a la formación de la ciudadanía socioambiental de los agentes de la sociedad de riesgo. En ese sentido, se realizó una investigación exploratoria y bibliográfica a la luz de Beck (2009; 2011), Beck, Giddens y Lash (1997), Giddens y Sutton (2017), entre otros. Los datos iniciales indican la necesidad de la incorporación de las prácticas ambientales en la Educación en Ciencias, para superar el entendimiento estricto de la visión física, química y biológica del conocimiento, dialogando en el contexto social, político y económico de los riesgos, puestos desde los avances científico-tecnológicos, volviéndose parte prioritaria y no complementaria de la formación docente.

Palabras clave: Riesgo. Educación Ambiental. Educación en Ciencias.

THE SOCIO-ENVIRONMENTAL APPROACH TO SCIENCE EDUCATION AS WAY TO THE CONSTRUCTION OF CITIZENSHIP WITHIN THE RISK SOCIETY

ABSTRACT: This article is based on the concept of Risk, approached in Society of Risk, by Ulrich Beck, and aims to reflect, in the scope of the school space, on how Education in Sciences can, through the contribution of Environmental Education, promote reflection on the risks arising from scientific and technological advances, in order to contribute to the formation of socio-environmental citizenship of the actors of that risk society. In this sense, an exploratory and bibliographic research was carried out in the light of Beck (2009; 2011), Beck, Giddens and Lash (1997), Giddens and Sutton (2017), among others. The initial data point to the need to incorporate environmental practices in Science Education, in order to overcome the strict understanding of the physical, chemical and biological view of knowledge, dialoguing in the social, political and economic context of the risks, based on the scientific and technological advances, becoming a priority and not a complementary part in teacher training.

Keywords: Risk. Environmental Education. Science Education. 


\section{INTRODUÇÃO}

Em sua obra Sociedade de Risco, o sociólogo alemão contemporâneo, Ulrich Beck (1986) apresenta uma reflexão sobre as transformações ocorridas, a partir da Revolução Industrial, na estrutura da sociedade moderna. Originalmente tais transformações relacionavam-se com a distribuição de riquezas materiais e hoje incluem também a distribuição dos riscos oriundos dos problemas ambientais, de saúde e outros decorrentes do desenvolvimento da ciência e da tecnologia. A este novo momento o autor denominou "modernidade reflexiva".

Nesse sentido, Beck (2011) aponta que o enfraquecimento das instituições sociais, como família, religião e classe social, e das relações de trabalho em direção a um processo de diluição das identidades coletivas, e o fortalecimento de uma individualização exacerbada, tendem a afetar a distribuição dos riscos de forma a fazer pesá-los mais sobre os indivíduos e menos sobre as organizações que os produzem, o que ele denomina de privatização dos riscos. Sua abordagem transdisciplinar se assemelha aos debates que norteiam as reflexões da Educação Ambiental crítica.

Vale ressaltar que a obra Sociedade de Risco foi publicada na década de oitenta do século XX, sob o olhar da Alemanha do pós-Guerra e no ápice da preocupação com as consequências do acidente radioativo ocorrido na usina de Chernobyl, localizada na Ucrânia, ex-União Soviética e construída em meados dos anos 1970. Todavia, no decorrer deste estudo serão vistos trabalhos mais recentes, em parceria com Anthony Giddens, desenvolvidos em torno do "risco" e da "modernidade reflexiva".

Acrescenta-se que os movimentos ambientalistas, também preocupados com os mesmos avanços e seus impactos no cenário mundial, constroem, dentre outras estratégias, a Educação Ambiental compreendida, desde sua origem, como prática educativa transdisciplinar e integradora do conhecimento. Sendo que, na década de setenta, três importantes eventos oficiais firmaram algumas diretrizes básicas para as ações dessa prática educativa. Diferentes países, que participaram da Conferência de Estocolmo (1972), da Conferência de Belgrado (1975) e da Conferência Intergovernamental sobre Educação Ambiental em Tbilisi (1977), na Geórgia, também então parte da antiga União Soviética, retrataram tais indicações nos documentos por eles gerados.

Diante disso, este artigo tem o objetivo de refletir, no âmbito do espaço escolar, sobre como a Educação em Ciências pode, por meio do aporte da Educação Ambiental, promover a reflexão sobre os riscos oriundos dos avanços científicos e tecnológicos, de modo a contribuir para a formação da cidadania socioambiental.

Cabe salientar que o conceito de risco, historicamente, sempre foi campo de estudo. Apesar disso, ainda que a obra de Ulrich Beck coloque o risco como tema central de todas as discussões, conceituá-lo, no limite dessa abordagem, mostra-se como um dos desafios colocados para este trabalho, que busca uma compreensão da temática de maneira efetiva na formação docente, considerando estes profissionais como atores de força no processo educativo.

Buscou-se construir um diálogo entre as abordagens da sociedade de risco e da modernidade reflexiva e aquelas oriundas dos debates estabelecidos pela Educação Ambiental, a fim de refletir sobre as possíveis contribuições desses campos para a inserção das temáticas relativas aos riscos e à formação da cidadania socioambiental na Educação em Ciências. 
Portanto, considerando o exposto acima, propõe-se, ainda, discorrer sobre as relações existentes entre o risco e a sociedade de risco; o risco e a ciência; o risco para as Ciências Naturais e para as Ciências Sociais; o risco e a Educação Ambiental; o risco e a Cidadania Socioambiental. Também é proposta deste trabalho enfatizar a importância de inserir este debate na formação dos professores de ciências.

\section{METODOLOGIA}

Levando em conta a necessidade de refletir sobre como a Educação em Ciências tem abordado o risco, no âmbito do espaço escolar, entendendo como necessário o debate acerca dele para o desenvolvimento socioambiental dos indivíduos, buscou-se, por meio de pesquisa exploratória e bibliográfica, elaborar uma compreensão mais próxima da temática investigada. De acordo com Gil (2008), a principal finalidade das pesquisas exploratórias é desenvolver ou esclarecer conceitos e ideias, aproximando-se da formulação de problemas mais específicos ou hipóteses para estudos posteriores.

Para isso, por meio também de uma pesquisa bibliográfica, à luz de Beck (2009; 2011), Beck; Giddens; Lash (1997), Giddens; Sutton (2017), dentre outros, buscou-se perceber as vertentes conceituais do risco em autores que dialoguem em concordância ou criticamente sobre o tratamento das questões relativas ao risco como conceito sociológico estruturante. Gil (2008, p. 50) afirma que "a pesquisa bibliográfica é desenvolvida a partir de material já elaborado, constituído principalmente de livros e artigos científicos".

\section{DISCUSSÃO}

\section{Risco e Sociedade de Risco}

O conceito de risco será consagrado como definidor de um novo tipo de sociedade por meio da obra Sociedade de Risco, de Ulrich Beck, em 1986. $\mathrm{Na}$ dimensão conceitual, o risco foi utilizado, e ainda é, em várias abordagens como estrutura para a caracterização social contemporânea. Segundo Lupton (2006), além da abordagem das ciências cognitivas, amparada nas avaliações técnico-científicas, que mensuram os riscos e seus efeitos, existem mais três correntes sociológicas: a primeira, a da teoria cultural/ simbólica, de Mary Douglas $^{1}$ (perspectiva mais antropológica); a segunda, a da governamentalidade ou socioconstrutivista, caracterizada por avaliar as formas de conhecimento, verdade e as disposições institucionais de risco, que recebe grandes contribuições a partir de Michel Foucault, ${ }^{2}$ Nikolas Rose ${ }^{3}$ e Pat O’Malley; ${ }^{4}$ e a terceira perspectiva, a da sociedade de risco de Ulrich Beck e Anthony Giddens. ${ }^{5}$

Dessa forma, o conceito de risco para pensar a sociedade é um entendimento comum, mas a forma como ele participa da construção social distinguir-se-á de acordo com o autor e sua corrente teórica. Giddens (2003) ressalta que risco não é o mesmo que infortúnio ou perigo, pois o "risco se refere a infortúnios ativamente avaliados em relação a possibilidades futuras" (GIDDENS, 2003, p. 33). O autor aponta o risco como uma dinâmica mobilizadora de uma sociedade propensa à 
mudança, assim, ao invés dessa sociedade confiar o seu próprio futuro à religião, a tradição ou aos caprichos da natureza, ela deseja determiná-lo.

Ao conceituar risco, Giddens e Sutton (2017) destacam que esse é um dos conceitos essenciais no campo das Ciências Sociais, numa perspectiva desvinculada do passado, desse modo, a definição prática de risco, proposto em Sociedade de Risco, seria a de "tentativas de evitar ou mitigar potenciais perigos, sobretudo os riscos fabricados que são produtos da atividade humana” (GIDDENS; SUTTON, 2017, p. 97). Assim, para esses autores, Beck (1944-2015) compreende que a morte da sociedade industrial acontece com o nascimento da sociedade de risco, em que a apropriação do entendimento de risco e os mecanismos de como evitá-lo tornam-se questões sociais estruturantes, assim, também, tudo que se refere ao meio ambiente, constitui uma reinvenção social.

Beck (2011) concebe o risco como resultado de ações humanamente produzidas, ligadas de maneira direta à modernidade reflexiva, que desenha a sociedade atual, considerando que a estruturação social ultrapassa a categorização de classes, emprego e família e se forma no contexto dos riscos. Nesse sentido, o autor ressalta que:

O risco representa o esquema perceptivo e cognitivo de acordo com o qual uma sociedade se mobiliza quando é confrontada com a abertura, incertezas e obstruções de um futuro autocriado e não é mais definida pela religião, tradição ou poder superior da natureza, perdendo a fé em um poder redentor utópico. (BECK, 2009, p. 4 - tradução nossa)

Isto posto, o conceito de risco relaciona-se de forma intrínseca com o de reflexividade, visto que a grande questão desse debate é como o processo de modernização torna-se reflexivo; ou seja, o mesmo processo de modernização é tema e é problema da sociedade. Aliado a esse aspecto, "riscos, assim como riquezas, são objeto de distribuição, constituindo igualmente posições - posições de ameaça ou posições de classe" (BECK, 2011, p. 31). Assim, em continuidade à perspectiva crítica dessa nova modernidade, Ulrich Beck, Anthony Giddens e Scott Lash, apresentam em Modernização Reflexiva, publicado em 1997, um diálogo acerca das especificidades e limites de suas respectivas defesas sobre o tema.

Nesse sentido, Beck, nessa mesma obra, afirma que o confronto entre as bases da modernização e as consequências promovidas por ela, não podem ser confundidas com o maior aprofundamento da reflexão social a partir da ampliação dos conhecimentos sobre os riscos, pois a transição do período industrial para esta modernidade ocorre na latência dos efeitos colaterais, despercebida ou mesmo indesejada. O tratamento e a assimilação das consequências dos avanços científicos e tecnológicos são confrontados sob novos padrões por se relacionar com o meio ambiente, cultura, ciência, progresso, economia e política.

Porém, é nesse contexto que o modo dos riscos, decorrentes desse tipo de produção de bens, podem ser distribuídos, evitados, controlados e legitimados. A respeito do que foi a sociedade industrial para a presente sociedade, Beck (2011) aponta que a distribuição de riquezas deixa de centralizar a organização social, dando lugar à distribuição de riscos.

Essa passagem — da distribuição de riquezas materiais para a distribuição dos riscos decorrentes do desenvolvimento da ciência e da tecnologia — ocorre sob duas 
condições: a primeira de carência material, pois é na superação da fome que a reflexão acerca dos riscos é potencializada; a segunda, pelos riscos e potenciais de autoameaça, que agora, embora ainda pesem desigualdades sociais, afeta a todos, inclusive os que os geraram como é o caso das mudanças climáticas e das pandemias, por exemplo. O novo paradigma da sociedade vigente seria o da busca por respostas sobre como evitar que a modernização leve a produção de ameaças e a riscos que ultrapassem os limites de aceitabilidade do que é considerado ecológico, médico, psicológico e social.

O conceito de sociedade de risco designa um estágio da modernidade em que começam as ameaças produzidas até então no caminho da sociedade industrial. Isto levanta a questão da autolimitação daquele desenvolvimento, assim como a tarefa de redeterminar os padrões (de responsabilidade, seguranças, controle, limitação do dano e distribuição das consequências do dano) atingidos até aquele momento, levando em conta as ameaças potenciais. (BECK; GIDDENS; LASH, 1997, p. 19)

Guivant (2016), uma das colaboradoras do último projeto de Beck, interrompido pelo seu falecimento, relata que Beck, na obra Sociedade de Risco, reconhece que a modernidade reflexiva é discutida num contexto europeu de Estado do bem-estar social e que ocorre algumas generalizações, como a universalização a partir da realidade europeia, porém manterá seu posicionamento, em produções posteriores, ${ }^{6}$ quanto à modernidade reflexiva no limite da abordagem de evitar os efeitos colaterais da industrialização.

Quanto ao conceito de risco, Guivant (2016) também afirma que Beck aponta uma definição mais complexa, pois irá compreendê-lo como um meio viabilizador para a antecipação de catástrofes planetárias, envolvendo além de riscos ambientais, os econômicos, agora também, aqueles oriundos do terrorismo; tudo em correspondência com as crises planetárias.

Beck argumenta que, de maneira fundamental, os indivíduos das sociedades modernas apresentam maior capacidade de refletir e interferir em sua existência social. Ele indica que as variações existentes sobre essa temática ocorrem em torno da cultura e da tradição, para Giddens; da estetização e da economia para Lash; e da política e subpolítica, para ele. $\mathrm{O}$ autor afirma, ainda, que as polêmicas entre os modernistas e pós-modernistas seriam superadas pelo percurso da modernidade reflexiva. Defende que a principal dificuldade para viabilizar a modernidade reflexiva é o desconhecimento pelo cidadão comum dos riscos a que está submetido. Desse modo, aponta para os limites dos debates e responsabilidades de como conhecemos e indica a necessidade de se pensar novos padrões de relacionamento com o meio ambiente, cultura, ciência, progresso, economia e política.

\section{0 risco e a ciência}

Segundo Giddens e Sutton (2017), o conceito de ciência surge relacionado à caracterização do conhecimento, sendo refletido distintamente em cada período. No século XIV, embora ainda não haja claramente uma definição de ciência como conhecemos hoje, o conhecimento sistematizado é compreendido como conhecimento anotado por escrito. No século XVII, seu entendimento foi de método 
de investigação; no século XIX ficou restrito às disciplinas de estudo do mundo físico, entre elas a Astronomia, a Física e a Química e, somente mais próximo ao fim desse período, expandiu-se para os temas sociais. Assim, para os autores, algumas escolas do positivismo começaram a partir do século XX, a fortalecer o espaço de alguns métodos, dentre eles, os de indução, dedução e verificação, para caracterizar o conhecimento dado como científico, sendo ele das ciências naturais ou sociais.

Nesse sentido, Giddens e Sutton (2017), afirmam que,

A ciência é quase sempre descrita como uso de métodos sistemáticos de investigação empiríca, a análise de dados, o pensamento teórico e avaliação lógica de argumentos com o intuito de desenvolver um bloco de conhecimento sobre determinado tema. (GIDDENS; SUTTON, 2017, p. 44).

Fundamentado nesse conceito, a Sociologia é dada como científica. Porém, parte dos cientistas entende que ela necessita de seus próprios métodos, pois sua existência já altera resultados obtidos. Ela é reflexiva e, muitas vezes, na própria execução da pesquisa leva à transformação dos indivíduos participantes.

O debate circundante sobre a temática de poluentes, toxinas do ar, água e alimentação, bem como todas as demais questões ambientais, para Beck (2011), são predominantemente abordadas pelas categorias e fórmulas das ciências naturais sob a alcunha de dispositivo orgânico. Essa abordagem leva ao que o autor denomina pauperização das análises sociais, políticas e culturais. Limitada às categorias químico-físico-biológico/técnicas, a partir de uma visão distanciada do homem e da natureza e sustentada pelos almejados alarmantes ganhos econômicos, oriundos da ciência e da tecnologia. Esse dispositivo orgânico tem se fortalecido, pois muito daquilo que prejudica a saúde e degrada o meio ambiente não é evidente a olhos nus, exigindo a posição confirmativa de um especialista.

Beck, em entrevista a Reverchon (2001), afirma que a ciência e a tecnologia causaram os principais problemas sociais da atualidade e que a especialização não atende à demanda gerada por esses problemas, advertindo para o perigo de uma discussão ambiental técnica, nos limites físicos, químicos e biológicos, tratada como dispositivo orgânico e sem considerar as relações sociais envolvidas. Afirmará, ainda, que uma das fragilidades da especialização é a dificuldade de se obter dados quantificáveis que não deixem dúvidas sobre os riscos. Nestes casos, costuma-se optar por correr o risco e não por esperar o aprofundamento das pesquisas, resguardando os indivíduos dos possíveis riscos, entendendo que a ausência de evidência dos riscos não pode mais ser justificativa para o adiamento de decisões e ações.

Nesse sentido, Demajorovic (2003) afirma que os problemas ambientais não são fatos do acaso, mas decorrentes de uma racionalidade que levou a profundas e múltiplas mudanças na organização social. O autor aborda a crise associada à modernidade surgida da Terceira Revolução Industrial, na qual a microeletrônica promove um estrondoso avanço na produtividade que leva a transformações sociais e problemas socioambientais. Ainda, para ele, a conquista da natureza levou à construção de uma nova percepção do homem sobre o meio ambiente. A natureza, antes tida como misteriosa e poderosa, tem hoje como principal característica a vulnerabilidade, por não acompanhar, em igualdade de condições, o crescimento econômico. 
Para Lima (1998), são nas abordagens objetiva e cartesiana dos dispositivos orgânicos que ocorrem a avaliação de risco, afastando-se, assim, da percep̧̧ão de risco, que se constrói no espaço da subjetividade. Tuan (2012) defende que sem a autocompreensão de percepções, atitudes e valores, não conseguiremos pensar em estratégias concretas para as questões ambientais e afirma que os cientistas tendem a negligenciar a subjetividade humana quanto a crenças e valores, por considerar que a função de estabelecer ligações com o mundo não humano já é muito complexa.

Pitanga (2016) também defenderá que o entendimento com que o mundo vivencia a crise da modernidade, estruturada na incessante busca pelo desenvolvimento tecnológico e pelo progresso científico, gera uma visão limitada dos prejuízos ocasionados por essa crise. Tais prejuízos são percebidos na degradação ambiental, entretanto não contemplam, na mesma proporcionalidade, a pobreza, as questões energéticas, as guerras e outros problemas globais. Assim, o autor apresenta sua inquietação sobre a crise relacionada ao conhecimento, que precisa ser superada com o entendimento ampliado a respeito das relações entre consumo, produção e natureza.

O trinômio produtividade-progresso-riqueza, almejado e defendido em tantos discursos, segundo Demajorovic (2003), começa a enfraquecer à medida que as consequências dessa modernidade começam a ser sentidas e, dessa forma, amplia-se a compreensão acerca da vulnerabilidade do conhecimento técnicocientífico em relação ao processo produtivo.

A ciência desloca-se de um entendimento, do século anterior, da cientifização simples ou primária, como solucionadora de problemas, para o que Beck (2011), no contexto da sociedade de risco, denomina de cientifização reflexiva ou secundária, entendida como solucionadora e produtora de risco. Nesse cenário, os riscos serão evidenciados ou invisibilizados de acordo com os interesses eminentes do mercado. Para ele,

A cientifização reflexiva abre, portanto, aos destinatários e usuários da ciência novas oportunidades de persuasão e de desenvolvimento nos processos de produção e emprego dos resultados científicos. Trata-se de um processo com um alto grau de ambivalência: ele contém a oportunidade de emancipação da práxis social em relação à ciência através da ciência; por outro lado, ele imuniza pontos de vista interessados e ideologias socialmente válidas contra pretensões científicas de esclarecimento e abre portas para uma feudalização da práxis científica de aquisição de conhecimento por meio de interesses econômicopolíticos e de novas "forças religiosas". (BECK, 2011, p. 237)

Assim, Beck (2011) defende a importância das Ciências Sociais em proximidade com as Ciências Naturais como meio mitigador de uma possível cegueira social. Para o autor, será na reflexividade buscada pelas Ciências Sociais que se constituirá o bom emprego das Ciências Naturais. O autor argumenta sobre a complexidade em torno do conhecimento técnico-científico, sendo, para ele, cada vez mais necessária a ciência (natural) na busca de conhecimento e, ao mesmo tempo, cada vez menos suficiente sozinha, salientando para contribuições advindas das ciências sociais.

Demajorovic (2003), referindo-se à teoria da ciência reflexiva de Ulrich Beck, considera que tem aumentado a expectativa em relação à ciência e à tecnologia para solucionar os problemas ambientais gerados na busca por maior produtividade. $\mathrm{O}$ 
autor aponta um aspecto central na crise da modernidade, que seria como desenvolver nos atores sociais, um componente reflexivo que permita a reconstrução dos fundamentos que moldaram a construção do conhecimento científico e tecnológico.

Desse modo, Demajorovic (2003) defende a importância do papel da educação na construção ou reconstrução dos valores, levando o conhecimento como nova economia e recurso gerador de riqueza. Ele justifica que a educação formal, fragmentada, no modelo atual, não atende sozinha às demandas do mundo complexo, destacando, então, a importância da colaboração da educação não formal.

Demajorovic (2003) reconhece a importância do papel da Educação Ambiental, uma vez que os problemas ambientais e os seus riscos, consequentemente, avolumam-se celeremente, ao contrário das resoluções, o que intensifica o argumento do valor da força de multiplicação das práticas sociais integradoras, que ampliam o acesso à informação, tanto nos limites da avaliação, quanto da percepção de risco. A Figura 1 busca representar a relação entre o risco e a sociedade contemporânea.

Figura 1. Relação entre os conceitos de Risco e Sociedade de Risco

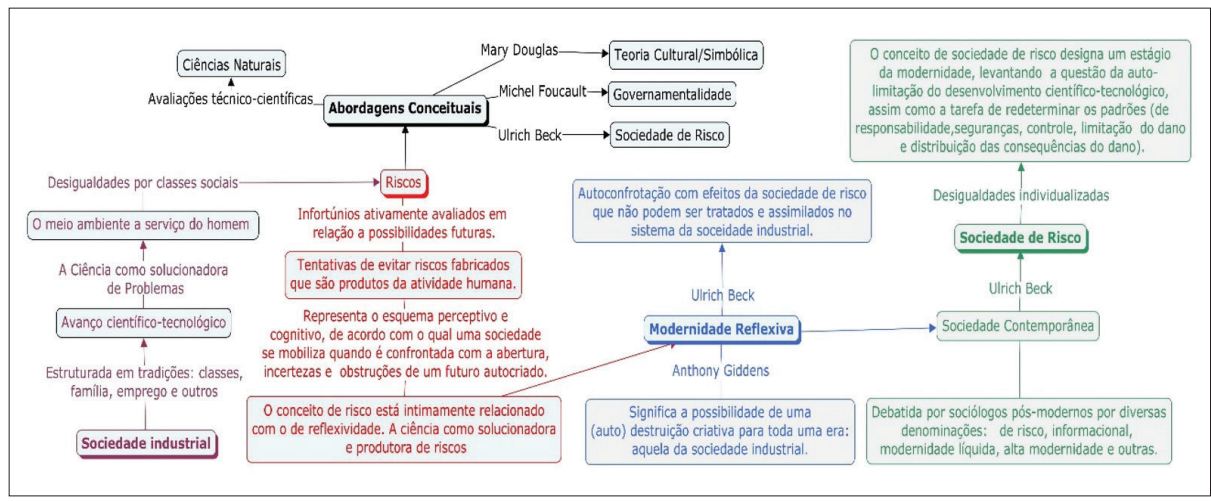

Fonte: Compilação dos autores(2019). ${ }^{7}$

\section{0 risco para as Ciências Naturais e para as Ciências Sociais}

Como referido anteriormente, muito das discussões sobre o meio ambiente, incluindo os produtos decorrentes dos avanços técnico-científicos, são abordadas nos limites das ciências naturais, negligenciando os aspectos sociais culturais e políticos. Com isso, Beck (2011) afirma que há uma discussão da natureza sem humanos. Dessa forma, observa-se a proximidade dos olhares de Beck e os movimentos ambientalistas, na busca reflexiva sobre as consequências sociais, políticas e culturais dos riscos da modernização.

O impacto causado ao meio ambiente pela indústria, levando prejuízo à saúde e à convivência das pessoas, para Beck (2011, p. 30) tem sua origem em sociedades altamente desenvolvidas e é marcado por um déficit do pensamento social. O autor argumenta, ainda, que por trás de números que indicam uma média de exposição de riscos, muitas vezes se mascara a realidade de pessoas desamparadas e/ou impossibilitadas de se movimentarem diante das consequências 
do avanço da ciência e da tecnologia. Em continuidade, Beck (2011) apontará que parte da distribuição de riscos e ameaças não é perceptível nem será para os afetados no mesmo momento de produção desses fenômenos, mas, sim, para seus descendentes. Esse fator diminui a crítica sobre tais consequências, reduzindo-a somente pela perspectiva dos dispositivos orgânicos.

Assim, "constatações de risco são uma ainda desconhecida e subdesenvolvida simbiose de ciências naturais e humanas, de racionalidade cotidiana e especializada, de interesse e fato" (BECK, 2011, p. 34). Desse modo, o autor defende a igualdade entre as vozes das ciências naturais e sociais nos debates acerca de riscos, reconhecendo o distanciamento entre as racionalidades das ciências naturais e sociais, mas ao mesmo tempo, afirmando a interdependência indissolúvel entre elas.

Um dos pontos polêmicos do argumento de Beck seria sua afirmação de que na Sociedade de Risco temos uma organização social não pautada em classes, mas em riscos. Para o entendimento do autor, não há negação da força das classes, mas a compreensão de que, embora haja riscos vinculados a posições sociais, também existem, e não são poucos, aqueles que ultrapassam os referidos limites. Nesse sentido, olhar os indivíduos em igualdade não fará uma correta correspondência com os argumentos expostos em Sociedade de Riscos. No entanto, é preciso atentar para riscos globalizados em que mesmo os ricos e poderosos não poderiam, pelo estado dos avanços da ciência e da tecnologia, blindar-se das consequências.

Na perspectiva da Sociedade de Risco, a sociedade não pode ser vista como autônoma em relação à natureza, e os problemas ambientais não estão apenas restritos ao meio ambiente, eles são também sociais, são problemas econômicos, culturais e políticos.

Na cientifização reflexiva, Beck (2011) argumenta sobre o estabelecimento de interações conflitivas, agora incorporando, além das ciências naturais, outras vozes, tais como a da administração, da política, da economia, ressaltando o ganho da transposição do conhecimento científico para práxis e para a política.

\section{A Ciência e a Educação Ambiental}

A utilização do termo meio ambiente, segundo Giddens e Sutton (2017), para descrever o mundo natural dentro do qual as sociedades existem é algo recente, em comparação ao uso da palavra "natureza", que normalmente tinha um emprego mais restrito. Os autores afirmam que sua utilização foi disseminada no período pós-guerra, por volta dos anos sessenta, pelos ambientalistas que questionavam os impactos da modernização e do urbanismo. Sociologicamente, este termo foi ganhando seu lugar nas discussões como as da chuva ácida, do efeito estufa e do aquecimento global.

Giddens e Sutton (2017) defendem que a sociedade e o meio ambiente devem ser compreendidos pelos aspectos das relações sociais e dos fenômenos naturais, sem minimizar nenhuma das contribuições. Para ele, os cientistas naturais precisam entender o comportamento humano para alcançarem, com os atores sociais envolvidos, uma intervenção bem sucedida sobre os fenômenos em estudo e, assim, contribuírem com suas técnicas.

Num breve panorama, Araújo (2007) descreve que será na segunda metade do século XX, que os estudos, movimentos e políticas ambientais irão se tornar pautas 
mais destacadas, tanto no cenário internacional quanto no nacional. De acordo com o autor, é de Estocolmo que resultam tanto o Programa das Nações Unidas para o Meio Ambiente (PNUMA) quanto o Programa Internacional de Educação Ambiental (PIEA), este conhecido por "Recomendação 96", que enfatizará a promoção da Educação Ambiental (EA) de maneira estratégica ao combate à crise do meio ambiente.

A década de setenta foi estruturante para a Educação Ambiental. Em 1974, no Seminário promovido pela UNESCO, alcançou-se o entendimento de que a EA não deve ser encarada como um ramo científico ou uma disciplina de estudos em separado, mas na qualidade de educação integral e permanente. Já em 1975, foi a "Carta de Belgrado" que, atenta para as consequências dos avanços da ciência e da tecnologia, veio estabelecer uma proposta mundial para a EA.

No segundo semestre de 1977, ocorre o mais importante evento internacional, a Conferência Intergovernamental sobre Educação Ambiental em Tbilisi, na exUnião Soviética, que tem a EA como tema central e a compreende como prática transdisciplinar. Essa Conferência firmou alguns dos princípios norteadores para o trabalho de EA ao considerar o ambiente em sua totalidade, natural, artificial, tecnológico e social (econômico, político, histórico-cultural, ético e estético).

A cada ano, eventos diferentes foram construindo a história da EA, havendo também a contribuição dos noticiários, repletos dos impactos decorrentes da modernização. Uma das manchetes jornalísticas que mais impactaram o mundo, no ano de 1986, foi a do acidente radioativo de Chernobyl, na Ucrânia, tema também abordado em Sociedade de Risco. Desse modo, na década de oitenta, o apelo para a necessidade de mudanças no modelo de desenvolvimento se mostrava bem estabelecido, sendo assunto de diversos encontros, dentre eles, a Conferência das Nações Unidas sobre Meio Ambiente e Desenvolvimento, conhecida por Eco-92, realizada, no Rio de Janeiro, após vinte anos da Conferência de Estocolmo.

Tal entendimento desenhará, no cenário brasileiro, alguns anos depois, a Política Nacional de Educação Ambiental (PNEA), instituída pela Lei n. 9.795/99, que em 2019 completou sua segunda década, repleta de desafios, avanços e retrocessos. Evidentemente essa história não finda, mas, como relato, daqui em diante será interrompida, neste texto, para continuidade da discussão sobre as diferentes concepções de Educação Ambiental.

Na década de 1990, a sustentabilidade protagonizará o discurso ambiental. Daí a Educação para o Desenvolvimento Sustentável (EDS) surge como proposta de completude à Educação Ambiental. A EDS se dispõe a combater a crise moderna no entendimento ecológico, social, político e econômico. A partir desse novo cenário, nem sempre serão comuns às expectativas, os meios e os fins da diversidade de correntes da Educação Ambiental, na compreensão da Educação para o Desenvolvimento Sustentável como um dos agentes desse campo.

Assim, da mesma forma que existe uma multiplicidade de abordagens do risco, observa-se o estabelecimento da Educação Ambiental, desde as diversas concepções, enquanto prática social transdisciplinar, a menos numerosa, mas também heterogênea concepção, como disciplina.

Souza e Salvi (2012) escrevem a respeito da Educação Ambiental e exemplificam de modo sintético na Figura 2, tendo foco ampliado no cenário nacional, na perspectiva de categorizar as correntes dessa área, salientando que elas não se limitam à esfera 
acadêmica e que essas correntes não expressam o limite da categorização existente. Contudo, Carvalho, Tomazello e Oliveira (2009) afirmam que as discussões privilegiadas sobre EA concentram-se na pós-graduação do sistema público universitário.

Figura 2. Esquema esboçando um cenário das práticas de $E A$

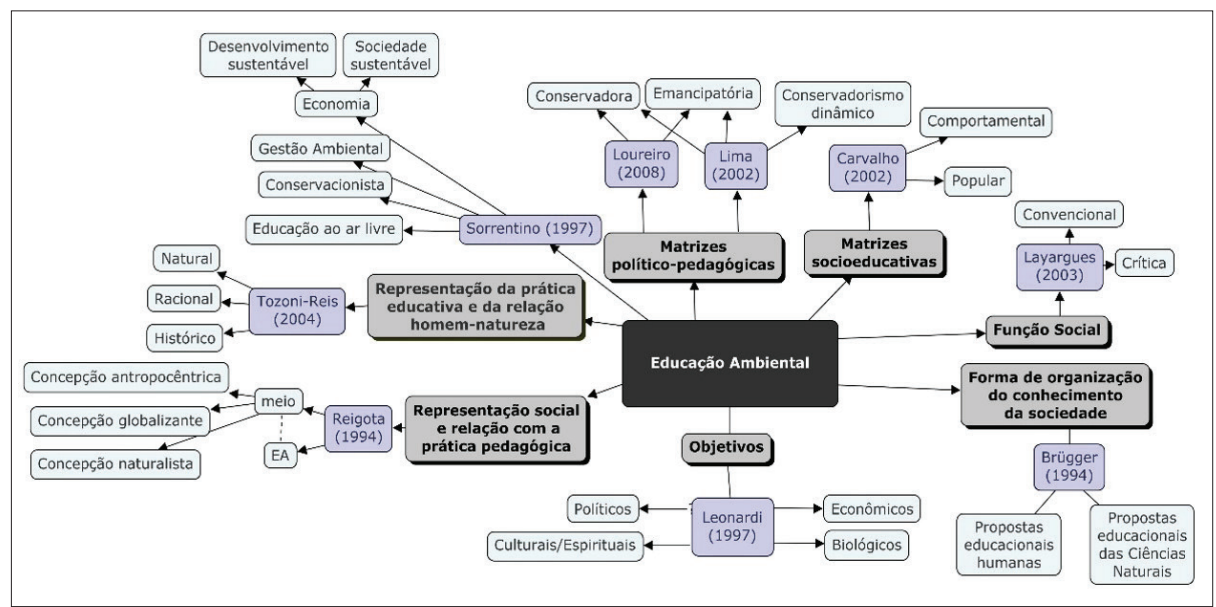

Fonte: Souza e Salvi (2012, p.116) - Adaptada.

De acordo com a Figura 2, pode-se observar que nas últimas três décadas houve grande contribuição para a EA com múltiplas vertentes. Considerando o âmbito acadêmico, muitos trabalhos percorrem uma ou mais linhas sobre as categorias apresentadas na Figura 2. Para os autores, a forma como a sociedade e a natureza se relacionam é um dos critérios para essa diferenciação.

De maneira menos branda, Pitanga (2016) destaca o campo de lutas entre a EA e a EDS. A crítica sobre a Educação Ambiental se dá por um reducionismo que não alcança uma visão educacional crítica global. Ainda, associa uma face romantizada e pouco assertiva frente às questões decorrentes da crise ambiental, impedindo, dessa forma, transformações necessárias. No que tange à EDS, a crítica ronda em torno da aceitação do conceito de Desenvolvimento Sustentável, que a fundamenta e se mostra polêmico na possibilidade de compatibilização de interesses da conservação do meio ambiente e do desenvolvimento econômico. Para o autor, o debate a partir da EDS pode atuar na perpetuação do modelo de desenvolvimento hegemônico neoliberal que mantém a lógica do consumo, privatiza riscos e desonera o Estado.

Desse modo, Pitanga (2016) afirma que o debate sobre EA e EDS gira em torno de três linhas. A primeira se desenvolve no grupo defensor de que a EDS é a continuidade evolutiva da EA. A segunda acredita que a EA contempla os aspectos abordados pela EDS. Por fim, a terceira linha entende a EDS numa abrangência maior que a EA.

Saito (2013) defende a manutenção da terminologia Educação Ambiental, mesmo sob as ponderações trazidas pelo Desenvolvimento Sustentável e pela Biodiversidade. Para o autor, a Educação Ambiental, desde Tbilisi em 1977, traz consigo a preocupação transdisciplinar, incluindo o aspecto social. Para ele, a 
discordância entre EA e EDS situa-se na base da estrutura ideológica. Ele afirma que para aqueles que defendem a EDS existe, nessa abordagem, o acolhimento das questões sociais, políticas e econômicas, agregando questões como fome, pobreza, trabalho e outros. Para outros autores existe, na adoção da EDS e no enfraquecimento da EA, o mascaramento das metas econômicas pelo slogan das metas ambientais.

Nesse sentido, Layrargues (2012) afirmará que a crise de identidade atual da EA tem sua origem na contradição entre a teoria e a prática, ocasionada pela ideologia dominante de um mercado que visa enfraquecer a crítica reflexiva sobre o consumo e utiliza do discurso ecológico para manter sua forma de produção. Por conseguinte, o autor afirma que a diversidade de correntes ideológicas atuantes na EA e a numerosa nomenclatura para a distinção de sentidos, configuram um desafio de classificação do campo. Ele promoverá a categorização de macrotendências a partir da abordagem político-pedagógica.

A primeira é a macrotendência conservacionista, representada pelas correntes conservacionista, naturalista, da Alfabetização Ecológica e pelo Movimento Sharing Nature. Dessa forma, incorpora temas como mudanças de comportamento individual a partir de percepções desenvolvidas mediante atividades variadas, como unidades de conservação, práticas de esportes em ambientes naturais, ecoturismo, trilhas interpretativas e outras. Essa macrotendência se fundamenta nos princípios filosóficos da ecologia profunda, amparados na afetividade e no desenvolvimento sistêmico, para o enfraquecimento da ideologia antropocêntrica.

Já a macrotendência pragmática é concebida em torno do conceito de Desenvolvimento Sustentável. Defende que a ciência e a tecnologia são aliadas para um desenvolvimento econômico que diz não à degradação ambiental. Aborda temáticas, como coleta seletiva, reciclagem dos resíduos, consumo sustentável, mudança climática e Economia Verde.

Finalmente, a macrotendência crítica, à qual Layrargues (2012) se associa, é de caráter emancipatório, popular e de transformação social. Aproxima-se da Ecopedagogia no embate à ideologia capitalista hegemônica de consumo e produção. Essa macrotendência se ampara nos pensamentos de Paulo Freire e de Karl Marx.

Aproximando-se da análise das macrotendências, pode-se relacionar a abordagem do risco, na sociedade atual, em proximidade à macrotendência crítica em que se busca perceber, por meio da reflexividade, a ciência como solucionadora e produtora de riscos. E essa mesma ciência, conduzida por interesses econômicos e não por neutralidade apresentada historicamente, pode invisibilizar ou alertar para os riscos.

Apoiado no enfoque do discurso, Layrargues (2002), em uma outra abordagem, vem nos apontar uma divisão do discurso ambientalista ao apresentar o discurso ecológico oficial e o discurso ecológico alternativo. Para ele, o discurso ecológico oficial, hegemônico, trata essa questão com um caráter técnico, com baixa reflexividade sobre as questões de mudanças de consumo e comprometendo-se aos interesses de mercado e não ambientais.

Com isso, Layrargues (2002) justifica que a atuação das escolas pode, em alguns casos, como em projetos ambientais que se limitam a troca de latas por materiais escolares, pouco colaborar para repensar o padrão de consumo, mas contribuirá com o mercado que lucra com a reciclagem. Desse modo, perde-se a potencialidade no espaço de formação socioambiental, que é a comunidade escolar, por uma adoção reducionista das práticas ambientais. 
De maneira semelhante, é possível associar o entendimento de Layragues sobre as possibilidades de discursos e as abordagens do risco. Muitas vezes, os discursos tentam invisibilizar ou minimizar os riscos, em detrimento de fatores como geração de empregos, renda e outros, podendo ser genuína ou falsamente explorados, de acordo com a hegemonia de mercado, desprezando, assim, os prejuízos sociais e ambientais que podem advir desses riscos, afastando-se da análise e da atividade social.

Retomando Layrargues (2002), não é que a reciclagem de latas seja a grande vilã das práticas ambientais na escola, acredita-se que, por vezes, o silenciamento do discurso ecológico alternativo, aquele que questiona, reflete e vincula-se às práticas sociais, não percebe a questão dos resíduos sólidos como cultural e não técnica, cabendo a reformulação do padrão de consumo vigente voltado para uma sociedade sustentável. Assim, a escola deve promover a discussão das questões ambientais na perspectiva de política pública, não dissociada da função social e dos valores culturais.

Por fim, o entendimento de que a educação é uma forte aliada na busca teórica e prática das questões ambientais sempre foi unânime, desde os primeiros eventos de repercussão mundial, e tem se perpetuado e adjetivado a educação como ambiental pela centralidade da relação sociedade e natureza. Nesse sentido, Pádua (2019) afirma que não se faria necessária a utilização da expressão composta: educação ambiental, pois se a educação é integral, não há outro meio de existência se não for contemplando a vida como um todo, já que somos parte e não estamos à parte, apenas utilizando a natureza. Com isso, podemos dizer que a Educação Ambiental traz, já no seu debate, esta compreensão da indissociabilidade entre ambiente, desenvolvimento e questões sociais, de forma que este é um ponto chave para construir o diálogo entre a sociedade de risco e as questões socioambientais.

\section{Cidadania Socioambiental: a indissociabilidade da Educação Ambiental e da Educação em Ciências}

A diversidade de correntes ideológicas encontradas na Educação Ambiental irá interferir diretamente na prática da Educação em Ciências. Não haverá, nesta última, a numerosa momenclatura vista na Educação Ambiental, mas a diversidade de abordagens distinguir-se-á pela reflexividade e pela crítica adotadas nas concepções estruturantes, consequentemente, interferindo no resultado do processo educativo.

Um outro conceito norteador tanto para a Educação Ambiental quanto para a Educação em Ciências é o da cidadania, que é considerado "um status social conferido aos membros de Estado-nação com base na residência” (GIDDENS e SUTTON, 2017, p. 307). Enquanto Estado-nação, Giddeens e Sutton (2017) compreendem uma grande combinação entre comunidade (nação) e uma forma territorial e política (Estado), estabelecendo-se no equilíbrio entre responsabilidades e direitos. Ainda para eles, trata-se de um conceito que inicialmente se divide em três tipos: a cidadania civil, com foco no respeito dos direitos de propriedade; a cidadania política, vislumbrando os direitos trabalhistas, da liberdade de expressão e do voto; e a cidadania social, compreendida dentro dos limites de bem-estar social e de direitos - como o da previdência social - que asseguram as pessoas em momentos de vulnerabilidade.

No entanto, nos últimos anos, diante das questões da modernização, estamos caminhando para uma quarta divisão: a da cidadania ambiental, "os 
cidadãos adquirem novos direitos de esperar um meio ambiente limpo e seguro, mas também possuem uma nova responsabilidade de não poluir o meio ambiente humano ou natural" (GIDDENS e SUT'TON, 2017, p. 307).

Nesse sentido, para Watanabe-Caramello e Kawakura (2014), a Educação Ambiental deve ser crítica, complexa e reflexiva (EACCR) de forma a promover a percepção da complexidade do mundo e a formação crítica-reflexiva dos indivíduos. E, considerando que os riscos são questões da atual sociedade, que não podem ser negligenciados nos espaços escolares, as autoras defendem a ideia de que problemas socioambientais precisam ser o ponto central da proposta curricular, e não uma atividade eventual, incorporando efetivamente a temática no cotidiano da sala de aula, permitindo, assim, por meio da reflexividade e da crítica, a mudança de paradigmas. Também não acreditam no êxito de uma educação que não contemple as questões sociais e que minimize a participação do professor e dos outros setores constituintes da escola.

Para Carvalho, Farias e Pereira (2011), a educação é entendida como importante meio de transmissão de culturas e de normas de organização da sociedade. Desse modo, as autoras posicionam a escola no lugar de um instrumento privilegiado na formação para a democracia, entendendo-a em sua função fundamental de promover uma educação para o desenvolvimento de competências ambientais para o efetivo exercício da cidadania.

No Brasil, o Artigo 5º incisos I, III, VI e VII, da Lei N 9.795/ 99, que institui a Política Nacional de Educação Ambiental, apresenta como alguns dos objetivos fundamentais da Educação Ambiental:

I - o desenvolvimento de uma compreensão integrada do meio ambiente em suas múltiplas e complexas relações envolvendo aspectos ecológicos, psicológicos, legais, políticos, sociais, econômicos, científicos, culturais e éticos;

III - o estímulo e o fortalecimento de uma consciência crítica sobre a problemática ambiental e social;

VI -o fomento e o fortalecimento da integração com a ciência e a tecnologia;

VII - o fortalecimento da cidadania, autodeterminação dos povos e solidariedade como fundamentos para o futuro da humanidade.

Nessa perspectiva, o direcionamento é para a Educação Ambiental transformadora que participe da formação de um cidadão socioambiental e que viabilize o desenvolvimento individual para uma efetiva participação nas políticas públicas.

Desse modo, observa-se a proximidade e indissociabilidade da Educação Ambiental e da Educação em Ciências. Praia e Jorge (2004) entendem que a Educação em Ciência deve ser o centro em uma comunicação com a Ciência, com a Ética (incluindo responsabilidade e solidariedade), com a Psicologia/Ciências da Educação, com a Sociologia da Educação (a participar as temáticas de CTS) e com a História/Filosofia da Ciência. Eles citam Chassot que acredita que a Educação em Ciência precisa, prioritariamente, promover a formação de indivíduos com 
preparo científico, que participem da sociedade exercendo sua cidadania.

Carvalho, Farias e Pereira (2011) afirmam que na justificativa da maior especialização forma-se a distância dialógica entre as ciências naturais e humanas, que tem levado a construções reducionistas para explicar as determinações do real que, por vezes, priorizam-se no arbitrário cultural ${ }^{8}$ e, outras, no biológico. Assim, "a função social das ciências oscila entre abertura e encerramento de possibilidades de ação e tais expectativas externas contraditórias fomentam conflitos e divisões no interior dos campos profissionais" (BECK, 2011, p. 238), levando à necessidade de uma pluralização da oferta de conhecimento científico e da crítica metodológica.

Cook (2015) entende que a pesquisa em educação científica deve envolver a comunidade local da escola, levando a ações de reflexão sobre os conceitos de conhecimento científico, praticantes de ciências e educação científica. O autor defende que a ideia hegemônica do empirismo, por trás das evidências e objetividade promulgadas pela ciência moderna ocidental, limita o processo de conhecimento. Ele, também, levanta a possibilidade de responsabilizar a filosofia do empirismo por ver frequentemente a ciência como um corpo de fatos que não se relaciona com outras formas de conhecimento, levando a um entendimento limitado de que o único conhecimento verdadeiro é o conhecimento científico.

Para Cook (2015), junto ao movimento intelectual do Iluminismo veio também o cientificismo, que considera que as ciências naturais predominam sobre todas as maneiras de conhecimento, posicionando a ciência numa marcante história de opressão e domínio relativa a outras formas de saber. Por isso, para ele, não causa espanto, diante do domínio de pensamento ocidental, que o debate e as políticas resultantes, relacionadas à sustentabilidade, geralmente sejam formadas de cima para baixo na organização social, ao invés de dar força aos mais impactados pelas práticas exauridas de produtividade decorrentes do desenvolvimento da ciência e da tecnologia. Assim, diante dos riscos e do entendimento da integração homemnatureza, a educação se distancia do cientificismo e da compreensão egocêntrica do mundo. Ainda, por ser relevante para a construção social, a educação deve concentrar esforços para que nas salas de aula de ciências haja espaço para reflexão sobre as implicações sociais e culturais de reivindicações e inovações científicas.

Ainda para Cook (2015), a Teoria da Ação Comunicativa de Habermas vem explicar o valor do diálogo na compreensão e no avanço científico, ao afirmar que a verdade nunca pode ser determinada por apenas um ator, mas na integração social, de maneira democrática, defendendo a quebra da dicotomia entre a subjetividade e a objetividade. Com esse olhar, ele propõe que haja reconhecimento das reivindicações sociais, compreendendo as diferentes perspectivas que levam ao entendimento mais preciso do mundo, sendo determinante que os estudantes tenham participação verdadeira nos diálogos da ciência, em vez de aguardar passivamente pela recepção de conhecimento.

Bourn, Hunt e Bamber (2017) entendem que a Educação científica é considerada uma área corriqueiramente de inclusão de temas de desenvolvimento sustentável na formação de professores, por exemplo, meio ambiente, energia, poluição e mudanças climáticas. Porém, os autores também apontam para limites existentes nas práticas docentes em relação à compreensão da interligação entre o 
ambiente, a energia, a educação e as preocupações políticas, econômicas e sociais relacionadas com o desenvolvimento sustentável. Daí, sugerem, citando Moseley et al. (2015) e Grunewwald (2003), como referenciais conceituais para abordar esses desafios, a consciência de lugar, que seria meio de percepção e desenvolvimento das questões sociocientíficas na formação de professores.

Figura 3. Abordagem sobre o Risco e Sociedade de Risco na Educação

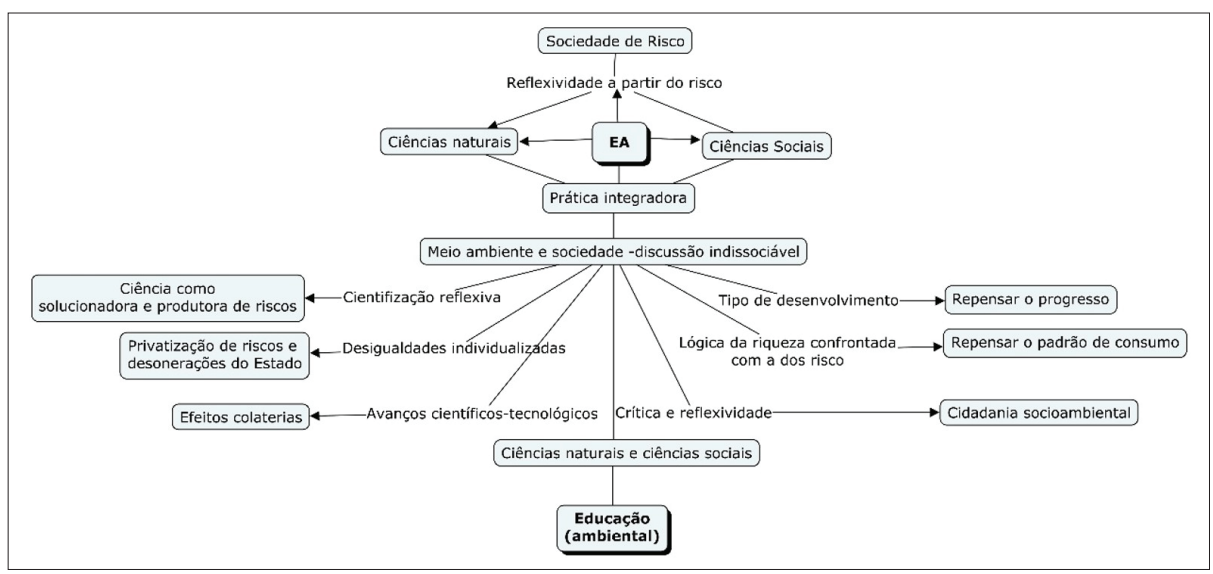

Fonte: Compilação dos autores(2019). ${ }^{9}$

Neste sentido, observa-se que tanto a Educação Ambiental quanto a Educação em Ciências podem trabalhar juntas para a construção de um cidadão com uma formação socioambiental que lhe possibilite compreender as questões desse universo, de forma a poder lidar com maior exigência e participação, particularmente, nas questões oriundas dos riscos produzidos pelas inovações científico-tecnológicas e outros que compõem a sociedade de risco (Figura 3). Também será no direcionamento de um mesmo entendimento, que suas práticas devem iniciar: das demandas locais e das vozes sociais. Assim, é na multiplicidade dos olhares e na transdisciplinaridade que será possível a compreensão mais precisa do mundo, sem o predomínio de nenhuma das vozes, mas na legitimação de todas elas.

\section{Formação de Professores}

De acordo com Bourn, Hunt e Bamber (2017), as áreas que discutem o meio ambiente e suas relações são complexas e frequentemente são vistas com baixa prioridade nas abordagens pedagógicas dentro da formação docente. Assim, para eles, entende-se que muitas vezes é difícil para um professor ganhar apoio para o desenvolvimento dos temas ambientais dentro das instituições. Eles acreditam que para um educador, em alguns países, conseguir formação para a prática ambiental, no espaço escolar, seria pelos cursos credenciados em nível de mestrado ou doutorado. Porém, essas são oportunidades nem sempre acessíveis para a maior parte dos professores. Também afirmam que nos exemplos de 
maior potencialidade para a incorporação das referidas temáticas na formação de professores, além do forte envolvimento individual, o Governo deve se posicionar como um aliado direto, mediante a oferta de apoio e financiamento.

Nóvoa (2017) alertará sobre a importância da formação de professores em três etapas: a formação inicial de professores, que ocorre dentro das universidades; seguida da indução profissional, fase de transição nos anos próximos à formatura, que deve ocorrer sob o apoio de um profissional mais experiente; e, depois, a formação profissional continuada, nos moldes da escola real/cotidiana. Para ele é necessário trabalhar as questões ambientais sem perder a lógica de convergência com as disciplinas, sem perder a importância do aprendizado das disciplinas compreendidas na realidade ambiental do mundo.

As iniciativas de alguns países, dentre eles o Brasil, para Bourn, Hunt e Bamber (2017), indicam que as abordagens ambientais se comunicam com outras dimensões, tais como saúde, gênero e direitos, promovendo o incentivo à crítica reflexiva e aos avanços científicos e tecnológicos; o uso de ferramentas pedagógicas que melhoraram o ambiente; o desenvolvimento das ações indivíduais e coletivas para a responsabilidade ambiental local, regional e global; a associação do conceito de desenvolvimento sustentável com o de Educação Ambiental. Desse modo, Bourn, Hunt e Bamber (2017) acreditam que as organizações da sociedade civil e as decisões políticas são fortemente influenciadas pelas ações decorrentes do trabalho educacional realizado para conhecimento da demanda local, por isso defendem que é na oferta de formação de professores que está um forte contributo nesse processo. Como sugestão, os autores alertam para a importância da inclusão de conhecimentos sobre os povos africanos e indígenas.

Por fim, Nóvoa (2019) argumenta que a escola, que funcionou por mais de 150 anos, não atende mais à demanda da contemporaneidade e acredita que essa escola não vive uma crise, mas sua extinção, devendo, sob a mesma nomenclatura, estabelecer-se como uma nova instituição. $\mathrm{O}$ autor menciona a importância de se pensar um modelo escolar que contemple a construção de uma vida em comum, numa escola articulada com outras instituições sociais, entendendo e respeitando os percursos individuais, com o objetivo de construir um sentido comunitário de lugar.

\section{CONSIDERACְÕES FINAIS}

O diálogo entre risco, Educação Ambiental e Educação em Ciências pode potencializar a compreensão dos estudantes sobre as localidades em que vivem, assim como os riscos que correm a partir da implementação de atividades econômicas, ampliando seu horizonte de participação social e de cidadania.

Acrescenta-se que a colaboração advinda do construto de uma crítica realizada pelas ciências naturais e sociais, de maneira igualitária, coloca como efetiva a prática transdisciplinar da Educação Ambiental. Assim, será na aproximação das ciências naturais e sociais, das objetividades e subjetividades, das avaliações e percepções e do entendimento sobre as diversidades ideológicas que se dará o anúncio, até mesmo de riscos mais invisibilizados e a viabilização de uma efetiva construção de cidadania.

Finalmente, por ser a escola um importante espaço de diversidades, a oferta de contínua formação dos professores deve ser tratada com prioridade e 
sensibilidade, pois estes são atores sociais que podem assegurar a potencialização da crítica e da reflexividade, ultrapassando as análises a partir dos dispositivos orgânicos. Tal direcionamento na formação dos professores leva à plenitude do exercício cidadão e auxilia no desenvolvimento de indivíduos ativos na construção de políticas públicas que garantam, acima de tudo, a continuidade da vida no planeta.

\section{REFERÊNCIAS}

ARAÚJO, T. C. D. Principais marcos históricos mundiais da educação ambiental. Ambiente Brasil, 2007. Disponível em: http://www.mobilizadores.org.br/wp-content/uploads/2014/10/ Principais-marcos-historicos-mundiais-da-educacao-ambiental.pdf. Acesso em: 18 nov. 2019.

BARBIERI, J. C.; SILVA, D. D. Desenvolvimento Sustentável e Educação Ambiental: Uma trajetória comum com muitos desafios. Revista de Administração Mackenzie, São Paulo, 12, n. 3, Maio/Jun. 2011, p. 51-82. Disponível em: https:// www.scielo.br/scielo.php?pid=S167869712011000300004\&script=sci_abstract \& tlng=pt. Acesso em: 30 ago. 2019

BECK, U. World at Risk. Cambridge: Polity Press, 2009.

BECK, U. Sociedade de Risco: rumo a uma outra modernidade. Tradução de Sebastião Nascimento. São Paulo: Editora 34, 2011.

BECK, U.; GIDDENS, A.; LASH, S. Modernização Reflexiva: política, tradição e estética na ordem social moderna. Tradução de Magda Lopes. São Paulo: Fundação Editora da Unesp, 1997.

BOURN, D.; HUNT, F.; BAMBER, P. Paper commissioned for the 2017/8 Global Education Monitoring Report, Accountability in education: Meeting our commitments. UNESCO - Global Education Monitoring Report, 2017.

BRASIL. Lei no 9.795, de 27 de abril de 1999. Dispõe sobre a educação ambiental, institui a Política Nacional de Educação Ambiental e dá outras providências. Presidência da República: Brasília, 1999. Disponível em: http://www.planalto.gov.br/ccivil_03/leis/19795.htm. Acesso em:20 de agosto 2019.

CARVAlHO, L. M. D.; TOMAZELlO, M. G. C.; OliVeIRA, H. T. D: Panorama da produção brasileira e alguns de seus dilemas. Caderno Cedes, Campinas, v. 29, n. 77, p. 13-27, jan./abr. 2009. Disponível em: https://www.scielo.br/scielo.php?pid=S0101-32622009000100002\&script=sci_ arttext. Acesso em: 18 set. 2019.

CATANI, A. M. et al. Vocabulário Bourdieu. 1ª ed. Belo Horizonte: Autêntica, 2017.

COOK, K. Grappling with wicked problems: exploring photovoice as a decolonizing methodology in science education. Cult Stud of Sci Educ, 26 jul. 2015, p. 581-592.

DEMAJOROVIC, J. Sociedade de Risco e responsabilidade socioambiental: Perspectivas para a educação corporativa. São Paulo: Senac, 2003.

GIDDENS, A.; SUTTON, W. P. Conceitos essenciais da sociologia. Tradução de Claudia Freire. $1^{a}$ ed. ed. São Paulo: Unesp Digital, 2017.

GIL, A. C. Métodos e Técnicas de Pesquisa Social. 6ª ed. São Paulo: Atlas S.A., 2008. 
GUIVANT, J. S. O legado de Ulrich Beck. Ambiente \& Sociedade, XIX, n. 1, p. 229-240, Jan./mar. 2016.

LAYRARGUES, P. P. O Cinismo da reciclagem: o significado ideológico da reciclagem da lata de alumínio e suas implicações para a educação ambiental. In: LOUREIRO, C. F. B.; LAYRARGUES, P. P.; CASTRO, R. D. S. Educação ambiental: repensando o espaço da cidadania. São Paulo: Cortez, p. 179-219, 2002.

LAYRARGUES, P. P. Para onde vai a Educação Ambiental? O cenário político ideológico da Educação Ambiental Brasileira e os desafios de uma agenda política crítica contra-hegemônica. Revista Contemporânea de Educação, 7, n. 14, ago./dez. 2012.

LIMA, M. L. Factores Sociais na percepção de riscos. Psicologia, Lisboa, v. 12, n. 1, p. 11-28, jan. 1998. Disponível em: http://www.scielo.mec.pt/scielo.php?script $=$ sci_arttext\& pid= S087420491998000100001. Acesso em: 25 out. 2019

LUPTON, D. Sociology and risk. In: MYTHEN, G.; WALKLATE, S. Beyond the Risk Society. 1 $^{\text {a }}$ ed. New York: Open University Press, Cap. 1, p. 11-24. 2006.

NÓVOA, A. Os Professores e a sua Formação num Tempo de Metamorfose da Escola. Educação \& Realidade, Porto Alegre, v. 44, n. 3, set. 2019. Disponível em: http://www.scielo.br/scielo. php?script=sci_arttext\&pid=S2175-62362019000300402\&lng=en\&nrm=iso. Acesso em: 24 out. 2019.

PÁDUA, S. O despertar de um senso de maravilhamento pela vida. In: LAVORATO, M. L. D. A. (org.). BenchMais4: as 388 melhores práticas em gestão socioambiental do Brasil, São Paulo: Biografia. Cap. 2, p. 37-39, 2019.

PITANGA, Â. F. Crise da modernidade, Educação ambiental, Educação para o Desenvolvimento Sustentável e Educação em Química Verde: (re)pensando paradigmas. Revista Ensaio, Belo Horizonte, v. 18, n. 3, set./dez. 2016, p. 141-159. Disponível em: https://www.scielo.br/pdf/epec/ v18n3/1983-2117-epec-18-03-00141.pdf. Acesso em: 05 nov. 2019

REVERCHON, A. Entrevista. Folha de São Paulo - Ciência, São Paulo, 20 Nov. 2001. Disponível em: https://www1.folha.uol.com.br/fsp/ciencia/fe2011200101.htm. Acesso em: 17 nov. 2019.

SAITO, C. H. Environmental Education and Biodiversity Concern: Beyond the Ecological Literacy. American Journal of Agricultural and Biological Sciences, 8, n. 1, p.12-27, 2013.

SOUZA, D. C. D.; SALVI, R. F. A Pesquisa em Educação Ambiental: Um Panorama sobre sua Construção. Revista Ensaio, Belo Horizonte, v. 14, n. 3, p. 111-129, set./dez. 2012. Disponivel em: https://www.scielo.br/pdf/epec/v14n3/1983-2117-epec-14-03-00111.pdf. Acesso em: 17 set. 2019

WATANABE-CARAMELLO, G.; KAWAMURA, M. R. D. Uma educação na perspectiva ambiental crítica, complexa e reflexiva. Revista Brasileira de Pesquisa em Educação em Ciências, v. 14, n. 2, 2014, p. 255-264. Disponível em: https://pdfs.semanticscholar. org/3cef/0811db4144e8e9ba44d639e611b476e4662a.pdf.

\section{NOTAS}

1 Mary Douglas em Risk and blame: essays in cultural theory (1992).

2 Michel Foucault em Il faut défendre la societé. Cours au Collège de France, 1976 (1997).

3 Nikolas Rose em Power of freedom. Reframing political thought (1999). 
4 Pat O'Malley em Governmentality and risk em Social theories of risk and uncertainty: an introdution (2008).

5 Anthony Giddens em As consequências da modernidade (1992).

6 Varieties of second modernity: Extra-European and European experiences and perspectives (2010).

7 Esquema elaborado a partir das leituras apresentadas.

8 "Arbitrário cultural" é o termo utilizado por Bourdieu para designar o fenômeno social que consiste em erigir a cultura particular de uma determinada classe social ("a classe dominante") em cultura universal. (CATANI; NOGUEIRA et al., 2017, p. 36)

9 Esquema elaborado a partir das leituras apresentadas.

\section{Submetido em 26/03/2020}

Aprovado em 07/09/2020

\section{Contato:}

Deine Bispo Miranda

Universidade de Brasília

Campus Universitário Darcy Ribeiro

Instituto de Química

Sala A1 93/20

CEP 70.910-900 